\title{
A ECONOMIA DO ESPÍRITO SANTO ESTÁ SOFRENDO UM PROCESSO DE DESINDUSTRIALIZAÇÃO?
}

\section{THE ECONOMY OF ESPÍRITO SANTO IS EXPERIENCING A PROCESS OF DEINDUSTRIALIZATION?}

\author{
Sávio Bertochi Caçador \\ Banco de Desenvolvimento do Espírito Santo - Vitória - ES - Brasil
}

\begin{abstract}
Resumo: Este trabalho analisa se a economia do Espírito Santo está passando por um processo de desindustrialização nas últimas décadas. Para isso, estimou-se um modelo empírico baseado em Rowthorn e Ramaswamy (1999). A base de dados foi a participação da indústria no Valor Adicionado Total - VAT e não se encontrou evidência de que a economia capixaba esteja sofrendo uma desindustrialização. Além disso, mostrou-se que a estrutura industrial capixaba é fortemente concentrada em commodities e estimativas demonstraram que índices de preços das commodities influenciaram positivamente, embora em pequena magnitude, a participação da indústria no VAT local.
\end{abstract}

Palavras-chave: Desindustrialização. Desenvolvimento regional. Espírito Santo.

Abstract: This paper examines whether Espírito Santo's economy is undergoing a process of deindustrialisation in recent decades. For this we have estimated one empirical model based on Rowthorn and Ramaswamy (1999), which examined the process of deindustrialisation in developed and developing countries, respectively. The database used has been the participation of industry in Total Added Value (TAV) and it is not found evidence that the local economy is suffering a deindustrialisation. In addition, it has been shown that the industrial structure of Espírito Santo is strongly concentrated in commodities and estimates have shown that commodity price indices have influenced positively, although on a small scale, the participation of industry in TAV.

Keywords: Deindustrialization. Regional development. Espírito Santo.

\section{INTRODUÇÃO}

Redes (St. Cruz Sul, Online), v. 20, n 3 - Suplemento, p. 341 - 362, set./dez. 2015341 
Nos últimos anos, tem-se observado uma preocupação crescente entre os economistas e o público em geral, sobretudo empresários, sobre um possível processo de desindustrialização da economia brasileira. Contudo, ainda não existe um consenso a respeito do assunto, conforme mostrou Oreiro e Feijó (2010). De um lado, têm-se os "novo-desenvolvimentistas", que defendem a tese de que a economia brasileira vem passando por um processo de desindustrialização nos últimos 20 anos e, por outro lado, têm-se os "economistas ortodoxos" que afirmam que as transformações pelas quais a economia brasileira passou nas últimas décadas não tiveram um efeito negativo sobre a indústria.

No bojo do debate nacional, empresários capixabas têm explicitado preocupação acerca dos impactos da desindustrialização na economia local. Em setembro de 2011, por exemplo, a Federação das Indústrias do Estado do Espírito Santo - Findes lançou a Carta da Indústria Capixaba (Findes, 2011), colocando a desindustrialização como um problema concreto da indústria capixaba. Todavia, a referida Carta não apresentou nenhuma evidência desse processo de mudança estrutural em território espírito-santense.

Levando em consideração o exposto anteriormente, o objetivo desse trabalho é averiguar se a economia do Espírito Santo está passando por um processo de desindustrialização por intermédio de uma análise empírica. $\mathrm{Na}$ literatura sobre o tema, existem duas definições: i) Rowthorn e Ramaswany (1999), para quem a desindustrialização é definida como um fenômeno caracterizado, principalmente, pela retração relativamente expressiva do emprego no setor manufatureiro vis-à-vis os demais setores, notadamente o de serviços; ii) Tregenna (2009) partiu de uma perspectiva kaldoriana para ampliar o conceito de desindustrialização, qualificando-o como um declínio sustentado do emprego e do valor adicionado da indústria como proporção do emprego total e do Produto Interno Bruto - PIB, respectivamente. Portanto, é utilizada a metodologia de Rowthorn e Ramaswamy (1999) para verificar se existe uma relação de "U" invertido entre a participação da indústria e o VAT per capita, bem como é feita uma análise descritiva das estatísticas disponíveis de emprego formal com base no conceito de Tregenna (2009).

O artigo está estruturado em cinco seções, incluindo esta parte introdutória. Na segunda seção, é feita uma breve revisão da literatura 
econômica brasileira sobre desindustrialização. Na terceira seção, são apresentadas estatísticas gerais da dinâmica setorial da economia capixaba. Já a quarta seção traz os procedimentos empíricos adotados e os resultados obtidos quanto à não existência de uma relação de "U" invertido entre a participação da indústria e o VAT per capita, bem como são apresentados elementos que explicam a não-desindustrialização da economia capixaba. A última seção ressalta as principais considerações finais do artigo.

\section{REFERENCIAL TEÓRICO}

Um dos primeiros estudos a apontar para a desindustrialização no país foi Marquetti (2002). Segundo dados apresentados para a indústria de transformação, a economia brasileira teria passado por um processo de desindustrialização nas décadas de 1980 e 1990 tanto em termos da participação do emprego como da participação no valor adicionado. Segundo Marquetti, a ocorrência desse fenômeno nesse período teria sido consequência do baixo investimento realizado na economia brasileira, particularmente na indústria. Ainda segundo esse autor, tal processo foi essencialmente negativo sobre os prospectos de crescimento da economia brasileira, haja vista que estaria associado à transferência de recursos e de trabalho da indústria para setores com menor produtividade do trabalho, gerando um menor crescimento do produto potencial no longo prazo.

Outro estudo que identificou a ocorrência de desindustrialização no Brasil nas décadas de 1980 e 1990 foi Bonelli (2005). Segundo dados apresentados por ele, a participação da indústria no PIB a custo de fatores teria se reduzido de $42,3 \%$, em 1985 , para apenas $31,4 \%$, em 1995. Essa queda foi basicamente o resultado da redução da participação da indústria de transformação no PIB, que passou de $31,62 \%$, em 1985, para 20,60\%, em 1995. Esse processo de "perda do peso relativo da indústria no PIB" foi causado pelas mudanças pelas quais passou a economia brasileira no final da década de 1980 e início da década de 1990, a saber: aumento da competição interna e externa, causado pela abertura comercial e financeira, privatização em diversos segmentos industriais e sobrevalorização da taxa real de câmbio no período 1995-1998. 
Feijó et al (2005) também apresentaram evidências de desindustrialização na economia brasileira durante as décadas de 1980 e 1990. Segundo esses autores, a participação no PIB da indústria de transformação passou de 32,1\%, em 1986, para 19,7\%, em 1998. Entretanto, o estudo indaga o caráter negativo dessa desindustrialização, dado que os resultados mostraram que a indústria brasileira manteve representatividade em todos os segmentos básicos conforme a classificação tecnológica.

Já Nassif (2008) avaliou que, apesar do declínio da participação da indústria no PIB do Brasil, as evidências empíricas mostram que as mudanças na sua estrutura econômica entre meados dos anos 1980 e 2005 não permitem caracterizar um processo de desindustrialização. Dado que não existem evidências nem de realocação generalizada de recursos em direção às indústrias baseadas em recursos naturais, nem de um padrão de especialização das exportações em bens intensivos em recursos naturais ou mesmo em trabalho, também não se pode concluir que o Brasil foi infectado por uma "nova doença holandesa".

Soares e Teixeira (2010) empregam o conceito de desindustrialização de Rowthorn e Ramaswamy (1999) para analisar o caso brasileiro. Para estes últimos, tal fenômeno pode ser explicado tanto por fatores internos quanto externos: os fatores internos estão relacionados às mudanças na estrutura de demanda, ao crescimento da produtividade mais rápido na indústria e à queda dos preços relativos neste setor; já os fatores externos estão associados ao crescimento do comércio Norte-Sul, que leva a uma redução do emprego industrial do Norte. Os autores concluíram que não há uma desindustrialização absoluta no Brasil, pois ambos os níveis de produto e emprego têm aumentado. Há uma perda relativa no produto e emprego, no entanto, esta não tem sido contínua para o período 1990-2007.

Por sua vez, Sonaglio et alli (2010) analisaram as evidências de um processo de desindustrialização na economia brasileira utilizando dados em painel. Concluíram que existe um possível processo de "reprimarização" da pauta de exportação brasileira, constatada pelo decréscimo de exportações de bens de alta tecnologia e aumento de bens não industriais, fato que também se relaciona com uma taxa de câmbio apreciada e com a manutenção de juros elevados. Os modelos estimados apontam que as exportações respondem às variações na taxa 
de câmbio de forma direta, implicando que uma apreciação cambial reduziria os saldos exportados.

Bonelli e Pessôa (2010) avaliaram a questão da perda de importância da indústria de transformação na economia brasileira a partir da análise da sua participação em relação a diversas variáveis e em âmbito internacional. Dessa forma, as perdas de peso da indústria (em preços correntes ou constantes) entre 1970 e 2009 sempre estiveram associadas a momentos de recessão e/ou crise externa (em geral, conjuntamente). No que tange ao emprego, também há indicações de que houve perda de peso, mas essa perda esteve concentrada nos anos de reforma estrutural do começo da década de 1990. E no que toca ao investimento fixo, não há evidência de desindustrialização desde meados da década de 1990. A análise da evolução da posição brasileira em relação a um padrão internacional mostra que o país estava muito acima desse padrão nos anos 1970 - isto é, tinha uma indústria muito maior do que seria justificado por um conjunto de variáveis indicativas do grau de desenvolvimento econômico, tecnológico, dotação de fatores e tamanho - e progressivamente tendeu para ele com o passar do tempo, estando, atualmente, pouco abaixo do padrão normal.

Soares et al (2011) destacam que a literatura recente tem sido pouco conclusiva a respeito dos determinantes do processo de desindustrialização vivenciado pela economia brasileira desde o final da década de 1980. Nesse sentido, eles testaram os determinantes diretos e indiretos do processo de desindustrialização. Entre os determinantes diretos destacam-se a formação bruta de capital fixo e o saldo da balança comercial como proporção do PIB. Os testes econométricos mostram que a taxa real de câmbio tem um forte efeito indireto sobre a perda relativa do emprego e do valor adicionado na indústria no período 1996-2008. Com efeito, a taxa real de câmbio afeta negativamente a participação da indústria no emprego e no valor adicionado devido aos seus efeitos sobre a formação bruta de capital fixo e o saldo da balança comercial. Daqui se segue, portanto, que a manutenção de uma taxa de câmbio sobrevalorizada no período em consideração é uma causa importante da desindustrialização verificada nesse período.

Por outro lado, Squeff (2011) discutiu a hipótese de desindustrialização brasileira a partir de uma perspectiva mais ampla do que a usualmente encontrada na literatura. Para tanto, usou indicadores relativos à produção, emprego, produtividade, exportação, importação e 
saldo comercial segundo a classificação por intensidade tecnológica da Organização para Cooperação Econômica e Desenvolvimento - OCDE. Dessa forma, embora tenha identificado que houve uma redução da participação da indústria no PIB nos últimos anos e que as exportações brasileiras estão bastante concentradas em produtos de baixo valor agregado, configurando indícios de que está em curso um processo de desindustrialização no Brasil, dados relativos à produção e emprego se mostraram contrários, em alguma medida, a este entendimento.

Cano (2012) analisou a desindustrialização em marcha no Brasil e alguns dos impasses da política macroeconômica. Para ele, a industrialização atingida nas décadas anteriores se deteriorou face à ausência de políticas industriais e de desenvolvimento e da conjugação de juros elevados, falta de investimento, câmbio sobrevalorizado e exagerada abertura comercial. Nesse contexto, ocorreu, segundo o autor, uma desindustrialização nociva que fragiliza o país e compromete sua economia por conta, sobretudo, da ausência de uma política macroeconômica consentânea com a política industrial. Por outro lado, Cano lembra que o subdesenvolvimento não representa uma etapa ou acidente de percurso, mas um processo que se inicia com a inserção no mercado internacional capitalista no século XIX e que, desse processo, o Brasil ainda não se libertou.

Por fim, Bacha (2013) mostra que a queda da participação da indústria de transformação no PIB, de $18,1 \%$, em 2005 , para $16 \%$, em 2011 , pode ser explicada como uma consequência da "bonança externa" - caracterizada por significativa entrada de capitais estrangeiros e um grande aumento do preço das exportações - que o país desfrutou no período. Ainda segundo ele, a indústria padeceu do que a literatura econômica denomina de doença holandesa, estando essa "doença" associada a uma valorização da taxa de câmbio real provocada pela melhoria das relações de troca e o aumento da transferência de recursos financeiros do exterior.

Do nível nacional para o regional, Scatolin et alli (2007) analisaram as evidências empíricas do processo de desindustrialização no Paraná vis-à-vis o caso brasileiro, ao passo que Cruz e Santos (2011) investigaram a desindustrialização em diversas regiões brasileiras. No primeiro estudo, os autores mostraram que o Brasil sofre uma desindustrialização desde os anos 1980. Todavia, no caso paranaense, a análise sugeriu que, apesar de ter apresentado uma queda da 
importância relativa no início da década de 1990, a mudança da sua estrutura produtiva proporcionou dois fenômenos importantes: (a) a recuperação dessa participação a partir de 1999, retomando o quantum observado em 1985; e (b) o aumento nesse setor do número de pessoas ocupadas e vínculos empregatícios, de acordo com os dados da Pesquisa Nacional por Amostra de Domicílio - PNAD e da Relação Anual de Informações Sociais - RAIS. Dessa forma, os resultados do Paraná não convergem com os constatados em nível nacional, destacando-se, principalmente, o comportamento relativo ao emprego, o que pode ser parcialmente explicado por um processo de desconcentração industrial ocorrido no Brasil ao longo dos anos 1990, favorecendo o Paraná.

Por fim, Cruz e Santos (2011) analisaram os efeitos da desindustrialização na configuração espacial da indústria. Para eles, a perda da importância da indústria de transformação, tanto no valor adicionado do PIB como no total do emprego, não é neutra em termos espaciais. Ainda que não seja conclusivo, os autores identificaram que, de fato, observa-se no Brasil uma relação não linear, em forma de "U" invertido, entre o peso da indústria e a renda per capita. Detalhando-se as microrregiões ganhadoras e perdedoras no processo de desconcentração industrial, concluíram que a maioria das microrregiões que mais perderam empregos está concentrada no Sudeste, em especial em São Paulo. Contudo, regiões com uma base industrial relevante, por exemplo, interior de São Paulo, ainda que tenham reduzido sua participação no emprego industrial, especializaram-se em indústrias de maior conteúdo tecnológico. Em vários casos, houve ganhos de empregos nessas indústrias capital-intensivas, ao passo que, para regiões ganhadoras, a conclusão é que, para indústrias de maior conteúdo tecnológico, economias de aglomeração parecem ser mais importantes que incentivos fiscais.

Baseando-se nas referências citadas anteriormente, este trabalho buscará evidenciar a existência de processo de desindustrialização na economia do Espírito Santo.

\section{DINÂMICA SETORIAL DA ECONOMIA DO ESPÍRITO SANTO}

Esta seção apresenta, de forma sucinta, os principais dados sobre a dinâmica setorial da economia capixaba. Parte-se do conceito de desindustrialização de Tregenna (2009), que o qualificou como um 
declínio sustentado tanto do emprego industrial como do valor adicionado da indústria, como proporção do emprego total e do PIB, respectivamente, para analisar o caso da economia capixaba nos últimos anos.

Nesse sentido, vale dizer que a economia capixaba foi relativamente bem estudada até o início dos anos 1990. Dentre os diversos trabalhos, cabe destacar: Rocha e Cossetti (1983); Bittencourt (1987); Rocha e Morandi (1991); Pereira (1998); e Rocha (1998). Estes trabalhos são de extrema importância para se entender o processo de industrialização local. Porém, salienta-se que são poucos os estudos que abordam o cenário econômico local recente, destacando-se Mota (2002) e Bittencourt (2006).

Tais estudos permitem delimitar claramente dois grandes ciclos de desenvolvimento da econômica capixaba:

- $1^{\circ}$ Ciclo: centrado na cafeicultura, sobretudo de base familiar, que predominou entre meados do século XIX e a década de 1950;

- $2^{\circ}$ Ciclo: caracterizado pela industrialização, que teve uma $1^{\text {a }}$ fase (1960-1975) baseada no crescimento e instalação de pequenas e médias empresas e uma $2^{\mathrm{a}}$ fase (1975-2000) baseada no crescimento e instalação de grandes empresas - os Grandes Projetos 1 - produtoras de commodities.

Segundo o documento "Espírito Santo 2025" (SEP, 2006), o ressurgimento da indústria petrolífera no Espírito Santo nos anos 2000 ensejou o início de um $3^{\circ}$ Ciclo de Desenvolvimento.

Como sintetiza a tabela 1, elaborada de acordo com a tipologia da indústria proposta por Ferraz et al (1995), a economia capixaba passou por uma profunda mudança entre 1960 e 2010. Nesse processo, visualiza-se o predomínio das commodities, que, em 2010, representavam quase $70 \%$ da produção industrial capixaba.

\section{Tabela 1. Participação relativa no Valor da Transformação Industrial}

\footnotetext{
$1 \mathrm{Na}$ literatura econômica capixaba, os termos Grandes Projetos e Grande Capital referem-se aos projetos industriais produtores de commodities realizados no estado entre meados dos anos 1970 e início dos 1980. Estes projetos compreenderam a construção da Aracruz Celulose, atualmente Fibria, da Samarco e da Companhia Siderúrgica de Tubarão (CST), atualmente denominada ArcelorMittal Tubarão, bem como a ampliação das atividades da Companhia Vale do Rio Doce (CVRD), atualmente Vale.
} 
do Espírito Santo (1960-2010) (\%)

\begin{tabular}{l|r|r|r|r|r}
\hline Grupos de atividades & 1960 & 1970 & 1985 & \multicolumn{1}{c}{1996} & \multicolumn{1}{c}{2010} \\
\hline Produtores de commodities & 8,1 & 17,9 & 49,9 & 53,5 & 69,8 \\
\hline Produtos duráveis de consumo & 0,4 & 2,3 & 6,9 & 1,5 & 0,3 \\
\hline Indústrias tradicionais & 71,1 & 55,2 & 27,4 & 25,8 & 11,3 \\
\hline $\begin{array}{l}\text { Indústrias difusoras de progresso } \\
\text { técnico }\end{array}$ & 1,7 & 1,6 & 7,0 & 3,2 & 4,1 \\
\hline Sub-total & 81,3 & 77,0 & 91,2 & 84,0 & 85,6 \\
\hline Demais setores & 18,7 & 19,8 & 8,8 & 16,0 & 14,4 \\
\hline Total & 100,0 & 100,0 & 100,0 & 100,0 & 100,0 \\
\hline
\end{tabular}

Fonte: Cálculos do autor com base nos dados de Pereira (1998, p. 135), para 1960; Mota (2002, p. 89), para 1970-1985; e IBGE (2012c), para os anos de 1996-2010.

Como consequência da especialização da indústria capixaba em commodities direcionadas para exportação, a economia capixaba possui um grau de abertura em torno de 50\% (Magalhães e Toscano, 2009). Cabe ressaltar, com base em Magalhães (2011), que a economia do Espírito Santo sente mais intensamente os impactos de choques nos preços de commodities do que o Brasil e outros estados por conta de seu alto grau de abertura e elevada participação da produção de commodities na indústria local.

O estudo da dinâmica setorial continua com a apresentação de dados de emprego formal e valor adicionado da indústria capixaba. Vale a ressalva de que a maioria dos estudos resenhados na seção 2 utilizam estatísticas da indústria de transformação. No estudo em questão, o uso desses dados não foi feito pela seguinte razão: estatísticas que mostram a subdivisão da indústria estão disponíveis apenas a partir de 1985, o que limita consideravelmente a capacidade de analisar um fenômeno estrutural e de longo prazo, como a desindustrialização. Em função disso, optou-se por trabalhar com dados globais da indústria.

Dando continuidade à análise, o gráfico 1 mostra a participação setorial do emprego formal no Espírito Santo entre 1985 e 2010 . Nele, nota-se que a parcela da indústria passou de 29,4\%, em 1985, para $23,2 \%$, em 2010 , uma redução de $6,2 \%$. Por sua vez, a participação do setor terciário ganhou 4,6\% em igual período, alcançando 73,4\% em 2010.

\section{Gráfico 1. Participação setorial do emprego formal no Espírito Santo,} (1985-2010) 


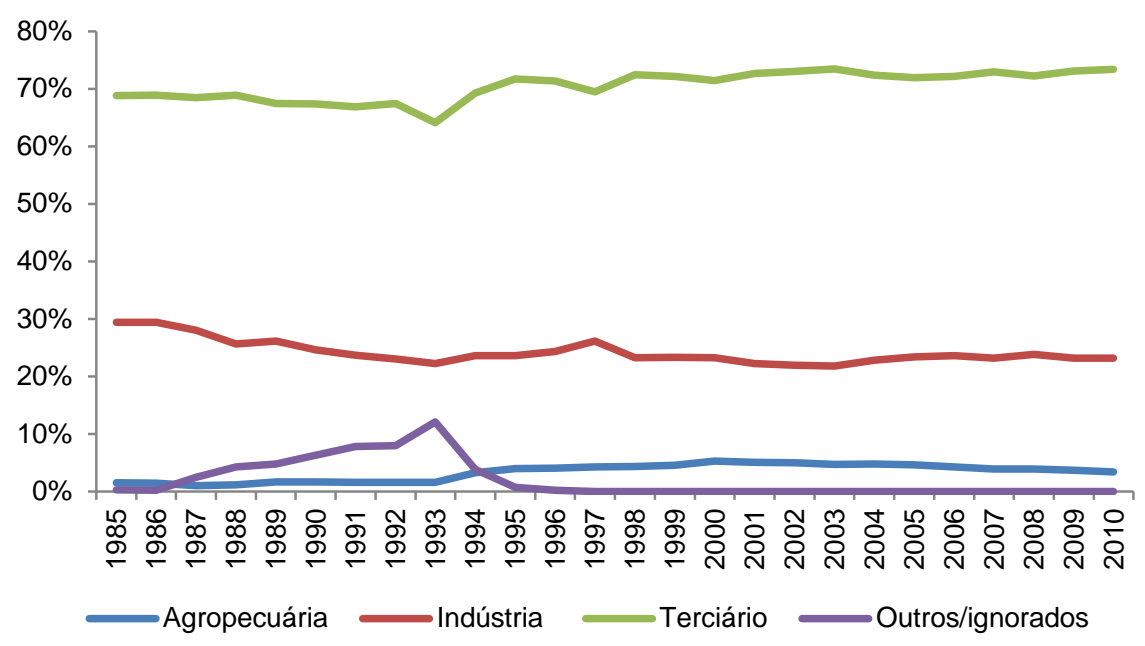

Fonte: Cálculos do autor com base nos dados do MTE/RAIS (2013).

Dando continuidade, o gráfico 2 mostra a participação setorial do VAT no Espírito Santo entre 1947 e $2010 .^{2}$ Ele aponta que participação da indústria passou de $6,7 \%$, em 1947, para 35,9\%, em 2010, uma expansão de $29,3 \%$ ao longo do período, embora ela tenha atingido um pico de $45,3 \%$ em 1992. Por sua vez, a participação do setor terciário ganhou 9,9\% em igual período, alcançando $57,7 \%$ do VAT em 2010.

2 No Anexo A.1 são apresentados os dados obtidos do IPEADATA para o Valor Adicionado de cada setor. Os dados de Contas Regionais no IPEADATA vão até 2010, por isso serão usadas estatísticas até este ano para as demais variáveis a fim de facilitar a comparação. 
Gráfico 2. Participação (\%) setorial do valor adicionado no Espírito Santo, (1947-2010)

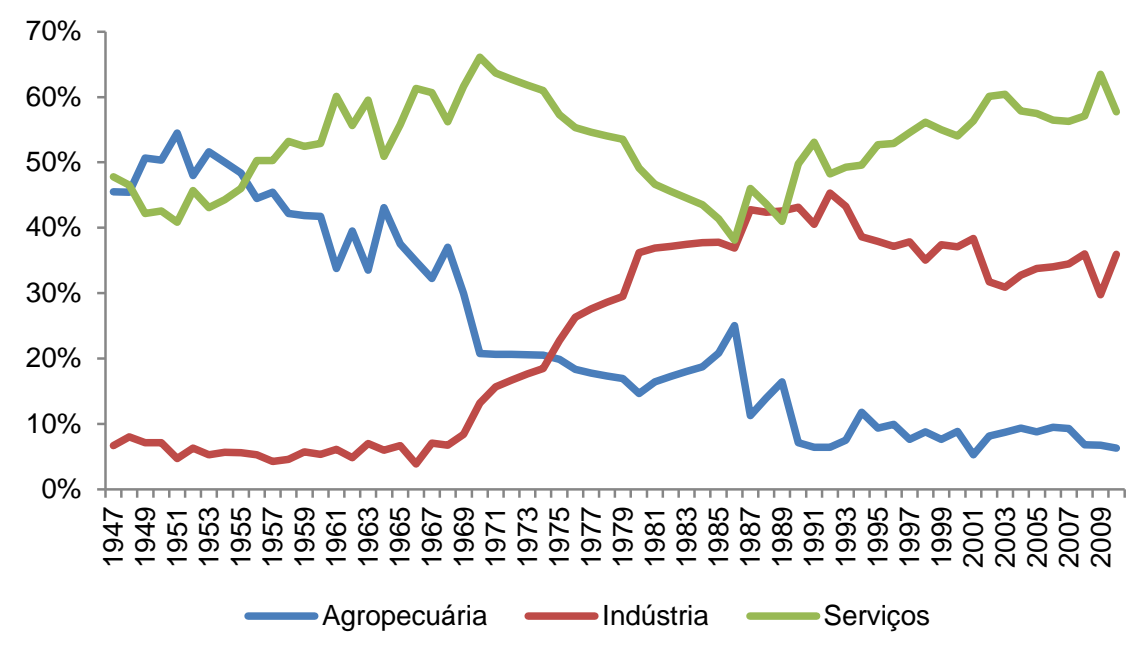

Fonte: Cálculos do autor com base nos dados do IPEADATA (2013a).

Em suma, com base apenas nos dados apresentados nos gráficos 1 e 2 não seria possível concluir que a economia capixaba passa por um processo de desindustrialização. Embora a indústria esteja perdendo participação relativa em termos de emprego, as estatísticas de valor adicionado mostram um aumento relativo desse setor, evidenciando, pois, uma expansão na sua produtividade e/ou a influência de algum processo cíclico, e não uma desindustrialização.

\section{METODOLOGIA}

\subsection{Estratégia empírica e base de dados}

Do ponto de vista empírico, o trabalho foi baseado em Rowthorn e Ramaswamy (1999), que analisaram o processo de desindustrialização em 18 países desenvolvidos, no período 1963-1994, usando o Método de Mínimos Quadrados Ordinários (MMQO). Dos diversos modelos estimados pelos autores, há interesse particular em estimar uma equação semelhante à equação 5 presente em Rowthorn e Ramaswamy (1999, p. 23), a saber:

$\log$ OUTSHARE $=\delta_{0}+\delta_{1} \log Y+\delta_{2}(\log Y)^{2}+\sum_{i>2} \delta_{i} Z_{i}$ 
onde OUTSHARE é a participação da indústria no PIB, $Y$ é a renda per capita e $Z$ é uma variável adicional que reflete a influência do comércio exterior e de outros fatores.

Dessa maneira, pretende-se estimar o seguinte modelo com dados da economia capixaba:

$\log ($ partind $)=\beta_{0}+\beta_{1} \log V A T_{p c}+\beta_{2}\left(\log V A T_{p c}\right)^{2}+\varepsilon$

onde "partind" é a participação da indústria no VAT, em porcentagem; "VATpc" é o VAT per capita a preços constantes de 2000, para o período de 1947 a 2010; e " $\varepsilon$ " o termo de erro. E "log", significa que as variáveis foram transformadas em logaritmo natural.

Em função da indisponibilidade de dados, optou-se por trabalhar com a variável "Valor Adicionado" e não com "PIB", conforme o fizeram Rowthorn e Ramaswamy (1999). Além disso, eles também estimaram um modelo usando a participação da indústria no total do emprego, o que não foi feito neste trabalho porque os dados disponíveis possuem uma quantidade pequena de observações. ${ }^{3}$ Outra observação que deve ser feita é que geralmente os estudos empíricos sobre desindustrialização, tanto no exterior como no Brasil, focam na indústria de transformação, ao passo que este estudo teve que trabalhar com a indústria como um todo por falta de séries temporais de longo prazo em menores níveis de agregação, conforme explicado na seção 3 .

Em linhas gerais, o objetivo da equação (1) é mostrar se a participação da indústria no VAT capixaba cresceu ou diminuiu à medida que o VAT per capita se expandiu ao longo dos anos, conforme mostra a tabela A.1 do Anexo. A Tabela 2 resume as estatísticas descritivas das variáveis utilizadas no estudo.

Tabela 2. Estatísticas Descritivas

\begin{tabular}{l|r|r}
\hline Variáveis & $\begin{array}{c}\text { Participação da } \\
\text { indústria (\%) }\end{array}$ & $\begin{array}{r}\text { Valor Adicionado per } \\
\text { capita (R\$ de 2000) }\end{array}$ \\
\hline Média & 23,65 & $3.894,64$ \\
Desvio-padrão & 14,81 & $2.469,30$ \\
Mínimo & 3,87 & 754,20 \\
Máximo & 45,33 & $8.569,56$ \\
\hline
\end{tabular}

${ }^{3}$ Ainda assim, os dados de empregos foram disponibilizados no Anexo A.2. 
$\mathrm{N}^{\circ}$ de observações 64 64

Fonte: Cálculos do autor com base nos dados do IPEADATA (2013a).

\subsection{Testes de raiz unitária}

Um importante passo da análise empírica a ser conduzida neste contexto equivale a checar a estacionariedade das séries temporais analisadas. Por conta disso, optou-se pela realização de testes de raiz unitária.

A Tabela 3 contém resultados dos testes Augmented Dickey-Fuller (ADF) (Dickey; Fuller 1981) e Phillips-Perron (PP) (Phillips; Perron 1988), cuja hipótese nula equivale à ocorrência de uma raiz unitária em cada série. No caso desses testes, todos os resultados foram obtidos a partir de especificações com uma constante e tendência temporal. O número de defasagens empregado em cada teste foi escolhido a partir do Critério de Informação de Schwarz, sendo reportado entre parênteses na tabela. 
Tabela 3. Testes de raiz unitária

\begin{tabular}{lrrrr}
\hline \multicolumn{1}{c|}{ Variável } & Teste ADF & \multicolumn{1}{c|}{ Teste PP } & \multicolumn{1}{c}{ Teste KPSS } \\
\hline \% indústria no VAT & $-0,85618^{\mathrm{ns}}$ & $-1,12841^{\mathrm{ns}}$ & $0,167839^{* * *}$ \\
\% indústria no VAT $\left(1^{\mathrm{a}}\right.$ & $(1)$ & $(1)$ & $(6)$ \\
diferença) & $-11,27660^{* * *}$ & $-10,79490^{* * * *}$ & $0,155354^{* * * *}$ \\
VAT $p c$ & $(0)$ & $(3)$ & $(5)$ \\
& $-1,52416^{\mathrm{ns}}$ & $-1,36222^{\mathrm{ns}}$ & $0,157769^{* * *}$ \\
VATpc $\left(1^{\text {a }}\right.$ diferença) & $(0)$ & $(1)$ & $(6)$ \\
& $-9,72826^{* * *}$ & $-9,62029^{* * *}$ & $0,099531^{* * *}$ \\
\hline
\end{tabular}

Fonte: Cálculos do autor com base nos dados da pesquisa.

Notas: (a) Todas as séries estão expressas em escala logarítmica natural.

(b) Valores críticos para esses testes estão contidos em Dickey; Fuller (1981), Mackinnon (1991) e Kwiatkowski et al. (1992).

(c) O número de defasagens empregado em cada teste (reportado em parênteses) foi escolhido de acordo com o Critério de Informação de Schwarz.

(d) Os termos $\left.\left(^{*}\right),{ }^{* *}\right)$ e $\left.{ }^{* * *}\right)$ denotam rejeição da hipótese nula de cada teste em níveis de 10\%, $5 \%$ e $1 \%$ de significância, respectivamente. 0 termo (ns) denota não significativo a $10 \%$.

Para fornecer maior robustez aos resultados desses testes, a tabela ainda inclui resultados referentes ao teste KPSS, cuja hipótese nula, contrariamente aos testes anteriores, equivale à hipótese de estacionariedade da série.

De acordo com os resultados contidos na tabela, é possível notar que as duas séries analisadas não são estacionárias em nível. Como as séries de participação da indústria no VAT e VAT $p c$ são integradas de ordens diferentes, o teste de cointegração não foi realizado entre as mesmas. ${ }^{4}$ Em decorrência disso, optou-se por trabalhar com transformações estacionárias das séries. Especificamente, no caso da análise em tela, as transformações utilizadas equivalem ao uso de primeiras diferenças dos logaritmos naturais.

\subsection{Resultados e discussões}

No que tange ao modelo (1), estimado pelo MMQO, a tabela 4 apresenta os principais resultados de três especificações distintas. Vale ressaltar que as estimativas foram feitas com as primeiras diferenças em logaritmo natural das variáveis em função dos resultados dos testes de raiz unitária apresentados na seção 4.2 .

\footnotetext{
4 Ver, a esse respeito, Engle e Granger (1987).
} 
Algumas observações sobre as estimativas precisam ser feitas:

- Os resíduos da especificação 1 apresentaram não normalidade, via teste Jarque-Bera, e autocorrelação, via teste Breusch-Godfrey. Este segundo problema foi corrigido pelo método de Newey e West (1987). Foi realizado o teste de White sobre os resíduos, que foram avaliados como homocedásticos.

- Na tentativa de corrigir a autocorrelação identificada na especificação 1, assumiu-se que a especificação 2 possui um processo autoregressivo de primeira ordem. Ainda assim, os resíduos dessa regressão apresentaram não normalidade.

- Por fim, na especificação, 3 os dados foram transformados em média móvel de três anos. Os resíduos dessa especificação apresentaram autocorrelação e heterocedasticidade, o que foi corrigido pelo método de Newey e West (1987).

Isso posto, a primeira observação que deve ser feita é que o teste F mostra que, globalmente, apenas a regressão da especificação 1 é estatisticamente significante. Contudo, os sinais de $\beta_{1}$ e $\beta_{2}$ dessa especificação não estão coerentes com o esperado, conforme estimativas de Rowthorn e Ramaswamy (1999). Dessa forma, não existe evidência robusta de uma relação do tipo "U" invertido entre a participação da indústria no VAT e o $\operatorname{VAT}_{p c}$ na economia do Espírito Santo no período em análise.

Tabela 4. Resultados do modelo 1

\begin{tabular}{l|rrrr}
\hline \multicolumn{1}{|c|}{ Variáveis } & Especificação $1^{\mathrm{b}}$ & \multicolumn{1}{c|}{ Especificação 2 } & \multicolumn{1}{c}{ Especificação 3 } \\
\hline$\beta_{0}$ & $0,0263^{\mathrm{ns}}(0,022901)$ & $0,0021^{\mathrm{ns}}(0,014455)$ & $0,0038^{\mathrm{ns}}(0,009967)$ \\
$\beta_{1}$ & $-4,1225^{* *}(1,932951)$ & $-0,9851^{\mathrm{ns}}$ & $-1,5249^{\mathrm{ns}}(2,361537)$ \\
$\beta_{2}$ & $0,2637^{* *}(0,263716)$ & $0,1000^{\mathrm{ns}}(0,111767)$ & $0,1558^{\mathrm{ns}}(0,163758)$ \\
& - & $-0,562434 \mathrm{~ns}$ & \\
AR (1) & & $(0,115315)$ & \\
Estatística F & $2,287866[0,11027]$ & $6,145206[0,001060]$ & $5,265554[0,007972]$ \\
$\mathrm{R}^{2}$ ajustado & 0,039887 & 0,201943 & 0,126329 \\
\hline
\end{tabular}

Fonte: Cálculos do autor com base nos dados da pesquisa.

Notas: (a) Todas as séries estão expressas em primeiras diferenças dos logaritmos naturais.

b) corrigido pelo método de Newey e West (1987).

c) *** para significativo a $1 \%$; ** para significativo a $5 \%$; * para significativo a $10 \%$; ns para não significativo;

d) erro padrão entre parênteses. 


\subsection{Em busca de explicações para a não desindustrialização da economia capixaba}

Como as estimativas feitas anteriormente não dão suporte à tese de que a economia do Espírito Santo está experimentando uma desindustrialização, pretende-se apresentar elementos que expliquem a falta de evidência desse fenômeno.

Uma possível explicação para a redução do peso da indústria na economia é a diferença de produtividade intersetorial. Segundo Baumol (1967), a indústria, por ser capital intensivo, seria o setor com maior produtividade, o que implica na realocação de mãodeobra para outros setores, entre eles, o de serviços.

Nessa linha, estimou-se a produtividade dos setores secundário, de comércio e de serviços do Espírito Santo. Depois de deflacionados os dados pelo Índice de Preços ao Consumidor Amplo - IPCA, a preços de 2011 , os cálculos foram feitos da seguinte forma:

a) Produtividade da indústria $=\frac{\text { Valor da Transformação Industrial }}{\text { Gastos com salários, outras remunerações e retiradas }}$

b) Produtividade do comércio $=\frac{\text { Margem de comercializaç̃ão }}{\text { Gastos com salários, outras remuneraçôes e retiradas }}$

c) Produtividade de serviços $=\frac{\text { Receita Bruta de Serviços }}{\text { Gastos com salários, outras remuneraçoes e retiradas }}$

Dessa forma, a tabela 5 apresenta a produtividade da indústria, do comércio e dos serviços do Espírito Santo para o período 1996-2010.5 Os dados, transformados em número-índice para facilitar a comparação, mostram os seguintes padrões empíricos: i) a produtividade da indústria cresceu mais do que a do comércio e a do setor de serviços; ii) a produtividade dos serviços sofreu uma redução entre 2002 e 2010.

Tabela 5. Produtividade da indústria, comércio e serviços do ES (19962010), em número-índice

\begin{tabular}{cccc}
\hline Anos & Indústria & Comércio & Serviços \\
\hline 1996 & 100,00 & 100,00 & n.d. \\
1997 & 115,05 & 122,15 & n.d.
\end{tabular}

5 O ideal para a análise em questão seria usar uma série de dados mais longa. Contudo, foram encontradas apenas estatísticas mais recentes, conforme exibido na tabela 2 . 


$\begin{array}{rrrr}1998 & 108,85 & 111,23 & \text { n.d. } \\ 1999 & 139,23 & 102,84 & \text { n.d. } \\ 2000 & 172,08 & 102,21 & \text { n.d. } \\ 2001 & 154,49 & 113,09 & \text { n.d. } \\ 2002 & 167,34 & 140,18 & 100,00 \\ 2003 & 197,72 & 136,95 & 96,88 \\ 2004 & 204,49 & 126,25 & 95,43 \\ 2005 & 211,65 & 130,91 & 102,71 \\ 2006 & 187,51 & 134,10 & 95,03 \\ 2007 & 170,05 & 112,05 & 108,86 \\ 2008 & 198,96 & 129,52 & 99,01 \\ 2009 & 131,55 & 124,75 & 90,91 \\ 2010 & 165,35 & 124,82 & 95,33\end{array}$

Fonte: Cálculos do autor com base nos dados IBGE (2012a, 2012b e 2012c).

Nota: n.d. significa não disponível.

Ademais, estimou-se também um modelo para verificar se algum fator externo afeta a participação da indústria no valor adicionado da economia capixaba. Com base no trabalho de Magalhães (2011), escolheu-se um índice de preço de commodities como proxy para esse fator externo. Em função disso, propõe-se estimar o seguinte modelo por meio do MMQO:

$\log ($ partind $)=\beta_{0}+\beta_{1} \log I P C+\varepsilon$

onde "partind" é a participação da indústria no VAT, em porcentagem; "IPC" é o índice de preços de commodities, em uma versão geral e outra focada em commodities minerais (IPEADATA, 2013b)6; e " $\varepsilon$ " o termo de erro. E "log" significa que as variáveis foram transformadas em logaritmo natural.

Em linhas gerais, o objetivo da equação (2) é mostrar se a participação da indústria no VAT capixaba cresceu ou diminuiu à medida que os índices de preço de commodities variaram entre 1980 e 2010. As duas séries de índices de preço de commodities usadas foram as mais longas que se encontrou disponível. A Tabela 6 resume as estatísticas descritivas das variáveis utilizadas.

\footnotetext{
${ }^{6}$ Metodologia de cálculo desse índice está em Nonnenberg e Lameiras (2005).
} 
Tabela 6. Estatísticas Descritivas

\begin{tabular}{l|c|c|c}
\hline Variáveis & $\begin{array}{c}\text { Participação da } \\
\text { indústria (\%) }\end{array}$ & $\begin{array}{c}\text { Índice de preços de } \\
\text { commodities geral (jan. } \\
\text { de 2002 = 100) }\end{array}$ & $\begin{array}{c}\text { Índice de preços de } \\
\text { commodities mineral } \\
\text { (jan. de 2002 = 100) }\end{array}$ \\
\hline Média & 37,38 & 136,76 & 142,04 \\
Desvio- & 3,75 & 46,80 & 73,08 \\
padrão & 29,77 & 96,43 & 83,41 \\
Mínimo & 45,33 & 282,78 & 401,75 \\
Máximo & 31 & 31 & 31 \\
\hline$N^{0}$ de & & 31 & \\
observações & & &
\end{tabular}

Fonte: Cálculos do autor com base nos dados de IPEADATA (2013b).

A Tabela 7 contém resultados dos testes ADF e PP, cuja hipótese nula equivale à ocorrência de uma raiz unitária em cada série. No caso desses testes, todos os resultados foram obtidos a partir de especificações com uma constante e tendência temporal. O número de defasagens empregado em cada teste foi escolhido a partir do Critério de Informação de Schwarz, sendo reportado entre parênteses, na tabela.

Tabela 7. Testes de raiz unitária

\begin{tabular}{c|c|c|c}
\hline Variável & Teste ADF & Teste PP & Teste KPSS \\
\hline & $-3,0071$ & $-3,0071$ & 0,1399
\end{tabular}

\% indústria no VAT

(0)

(4)

$\%$ indústria no VAT ( $1^{\text {a }}$ diferença $)$

$-7,0854 * * * \quad-\quad 0,1666^{* * *}$

Índice de commodities geral

Índice de commodities geral ( $1^{\mathrm{a}}$ $-6,1263 * * *$

diferença)

Índice de commodities mineral

Índice de commodities mineral ( $1^{\mathrm{a}}$ diferença)

Fonte: Cálculos do autor com base nos dados da pesquisa.

Notas: (a) Todas as séries estão expressas em escala logarítmica natural.

(b) Valores críticos para esses testes estão contidos em Dickey; Fuller (1981), Mackinnon (1991) e Kwiatkowski et al. (1992). 
(c) O número de defasagens empregado em cada teste (reportado em parênteses) foi escolhido de acordo com o Critério de Informação de Schwarz.

(d) Os termos $\left(^{*}\right),(* *)$ e $(* * *)$ denotam rejeição da hipótese nula de cada teste em níveis de $10 \%$, 5\% e 1\% de significância, respectivamente.

A título de fornecer maior robustez aos resultados oriundos de tais testes, a tabela ainda inclui resultados referentes ao teste KPSS, cuja hipótese nula, contrariamente aos testes anteriores, equivale à hipótese de estacionariedade da série.

Conforme os resultados contidos na tabela, é possível notar que as três séries analisadas não são estacionárias em nível. Como as séries de participação da indústria no VAT, índice de commodities geral e índice de commodities mineral são integradas de ordens diferentes, o teste de cointegração não foi realizado entre as mesmas. ${ }^{7} \mathrm{Em}$ decorrência disso, optou-se por trabalhar com transformações estacionárias das séries em primeiras diferenças dos logaritmos naturais.

No que tange ao modelo (2), estimado pelo MMQO, a tabela 8 apresenta os principais resultados de três especificações distintas. Vale ressaltar que as estimativas foram feitas com as primeiras diferenças em logaritmo natural das variáveis em função dos resultados dos testes de raiz unitária apresentados anteriormente. Testes nos resíduos foram conduzidos nas duas estimativas, que apresentaram normalidade, homocedasticidade e não autocorrelacão.

Tabela 8. Resultados do modelo 2

\begin{tabular}{l|r|r}
\hline \multicolumn{1}{c|}{ Variáveis } & Especificação 1 & \multicolumn{1}{c}{ Especificação 2 } \\
\hline \multirow{2}{*}{$\beta_{0}$} & $-0,005656^{\mathrm{ns}}$ & $-0,007146^{\mathrm{ns}}$ \\
& $(0,013162)$ & $(0,013800)$ \\
$\beta_{1}$ & $0,312879^{* * *}$ & $0,174741^{* *}$ \\
& $(0,111688)$ & $(0,074867)$ \\
Estatística $F$ & 7,847654 & 5,447708 \\
& {$[0,009125]$} & {$[0,026996]$} \\
$\mathrm{R}^{2}$ ajustado & 0,191021 & 0,132975 \\
\hline
\end{tabular}

7 Ver, a esse respeito, Engle e Granger (1987).

Redes (St. Cruz Sul, Online), v. 20, n 3 - Suplemento, p. 341 - 362, set./dez. 2015359 
Fonte: Cálculos do autor com base nos dados da pesquisa.

Notas: (a) Todas as séries estão expressas em primeiras diferenças dos logaritmos naturais.

b) *** para significativo a $1 \%$; ** para significativo a $5 \%$; * para significativo a 10\%; ns para não significativo.

c) erro padrão entre parênteses.

Depois disso, a primeira observação que deve ser feita é que o teste $\mathrm{F}$ mostra que globalmente as duas regressões são estatisticamente significantes. Quanto aos coeficientes, o $\beta_{1}$ foi estatisticamente significante e os resultados foram coerentes com a realidade econômica local. Na primeira especificação, cada variação de $1 \%$ no índice de commodities geral acarreta uma variação de 0,3128\% na participação da indústria no VAT capixaba. Já na segunda especificação, cada variação de $1 \%$ no índice de commodities mineral causa uma variação de $0,1747 \%$ na participação da indústria no VAT capixaba.

Embora os coeficientes das duas regressões tenham uma magnitude pequena, eles são positivos e condizentes com as estimativas apresentadas na tabela 5 , referentes ao modelo 1 , que não apontou evidências de processo de desindustrialização na economia capixaba. Em outras palavras, a expectativa era de que os preços das commodities influenciassem positivamente a participação da indústria no VAT, o que foi confirmado pelas regressões apresentadas na tabela 8.

\section{CONSIDERAÇÕES FINAIS}

Existe uma quantidade razoável de estudos sobre o processo de desindustrialização no Brasil e poucos textos que tratam das especificidades regionais desse processo. Nesse sentido, considera-se justificável um estudo sobre o tema para o Espírito Santo, cuja estrutura industrial é peculiar, dado que as grandes plantas produtoras e exportadoras de commodities possuem um peso elevado na estrutura industrial local.

Por conta disso, o objetivo deste trabalho é analisar se a economia do Espírito Santo está passando por um processo de desindustrialização por meio de uma análise empírica. Os principais resultados encontrados foram os seguintes:

a) em termos de análise gráfica: i) a participação da indústria no emprego formal do Espírito Santo passou de 29,4\%, em 1985, para 
$23,2 \%$, em 2010 , uma redução de $6,2 \%$; ii) quanto ao valor adicionado, a participação da indústria passou de $6,7 \%$, em 1947 , para $35,9 \%$, em 2010 , uma expansão de $29,2 \%$ ao longo do período, embora ela tenha atingido um pico de $45,3 \%$ em 1992 ;

b) no que diz respeito à produtividade, os dados apurados de 1996 a 2010 mostram que a da indústria cresceu mais do que a do comércio e a do setor de serviços;

c) estimando um modelo baseado em Rowthorn e Ramaswamy (1999), não se encontrou evidências de um processo de desindustrialização no estado;

d) por fim, foram feitas regressões para estimar o efeito dos preços das commodities na participação da indústria capixaba no VAT, cujo efeito foi positivo.

Em suma, com base nas estatísticas apresentadas e nos modelos estimados, pode-se afirmar que a indústria capixaba não padece de um problema de desindustrialização. As variações da participação da indústria em termos de emprego formal e valor adicionado são explicadas, respectivamente, por: i) expansão da produtividade, inclusive com crescimento superior ao terciário; ii) relação positiva com a variação do preço de commodities.

Vale ressaltar que a análise feita neste trabalho se restringe mais aos aspectos macroeconômicos da economia do Espírito Santo e possui limitações, principalmente na base de dados: 1) de valor adicionado, em função das várias mudanças de metodologia ao longo dos anos; e 2) de quantidade de empregos formais, já que deve se lembrar sempre que o grau de informalidade no mercado de trabalho, seja no país como um todo, seja no estado, ainda é muito elevado. Ademais, outros enfoques devem ser usados para pesquisas no futuro como, por exemplo, o da Economia Industrial, para se averiguar, dentre outras coisas, em que medida a indústria capixaba tem optado pela especialização de serviços, levando a indústria a terceirizar com maior intensidade as atividades não diretamente ligadas à produção.

\section{REFERÊNCIAS}

BACHA, E. "Bonança externa e desindustrialização: uma análise do período 2005-2011". In: BACHA, E.; BOLLE, M. B. (orgs.). O futuro da 
indústria no Brasil: desindustrialização em debate. Rio de Janeiro: Civilização Brasileira, 2013. cap. 4.

BAUMOL, W. J. "Macroeconomics of unbalanced growth: the anatomy of urban crisis". American Economic Review, v. 57, p. 415-426, 1967.

BITTENCOURT, G.. A formação econômica do Espírito Santo: o roteiro da industrialização, do engenho às grandes indústrias. Rio de Janeiro: Cátedra, 1987.

História geral e econômica do Espírito Santo: do engenho colonial ao complexo fabril-portuário. Vitória: Multiplicidade, 2006.

BONELLI, R. "Industrialização e Desenvolvimento: notas e conjecturas com foco na experiência do Brasil". Conferência de Industrialização, Desindustrialização e Desenvolvimento, Federação das Indústrias do Estado de São Paulo, Agosto de 2005.

BONELLI, R.; PESSÔA, S. A. Desindustrialização no Brasil: um resumo da evidência. Texto para discussão $n^{0} 7$. Rio de Janeiro-RJ: Instituto Brasileiro de Economia, 2010.

CANO, W. Desequilíbrios regionais e concentração industrial no Brasil: 1930-1995. 2. ed. Campinas: Instituto de Economia da Unicamp, 1998. $421 \mathrm{p}$.

A desindustrialização no Brasil. Texto para discussão $\mathrm{n}^{\circ} 200$. Campinas-SP: Instituto de Economia Unicamp, 2012.

CRUZ, B. O.; SANTOS, I. R. S. Dinâmica do emprego industrial no Brasil entre 1990 e 2009: uma visão regional da desindustrialização. Rio de Janeiro-RJ: Instituto de Pesquisa Econômica Aplicada, Texto para discussão $n^{\circ} 1673,2011$.

DICKEY, D. A.; FULLER, W. A. "Likelihood ratio statistics for autoregressive time series with a unit root". Econometrica, v. 49, n. 4, p.1057-1073, 1981. 
ENGLE, R. F.; GRANGER, C. W. J. "Co-integration and error-correction: representation, estimation and testing". Econometrica, v. 55, n. 1, p. 251-276, 1987.

FEDERAÇÃO DAS INDÚSTRIAS DO ESTADO DO ESPÍRITO SANTO (Findes). Carta da indústria capixaba 2011. Disponível em: <http://www.ideies.org.br/midias/pdf/Carta_da_Industria_Capixaba201 1.pdf $>$. Acesso em: 05 de outubro de 2012.

FEIJÓ, C.A; CARVALHO, P.G; ALMEIDA, J. S. G. Ocorreu uma desindustrialização no Brasil? São Paulo: IEDI, Novembro de 2005, mimeo.

FERRAZ, J. C.; KUPFER, D.; HAGUENAUER, L. Made in Brazil: desafios competitivos para a indústria. Rio de Janeiro: Editora Campus, 1995.

INSTITUTO BRASILEIRO DE GEOGRAFIA E ESTATÍSTICA (IBGE, 2012a). Pesquisa Anual do Comércio (PAC) - 1996/2010. Disponível em: $<$ www.ibge.gov.br>. Acesso em: 10 de outubro de 2012.

(IBGE, 2012b). Pesquisa Anual de Serviços (PAS) - 2002/2010. Disponível em: <www.ibge.gov.br>. Acesso em: 10 de outubro de 2012.

(IBGE, 2012c). Pesquisa Industrial Anual (PIA) - 1996/2010. Disponível em: <www.ibge.gov.br>. Acesso em: 10 de outubro de 2012.

IPEADATA (IPEADATA, 2013a). Estatísticas populacionais e socioeconômicos do Espírito Santo e de seus municípios. Disponível em: <http://www.ipeadata.gov.br>. Acesso em: 30 de maio de 2013.

IPEADATA (IPEADATA, 2013b). Estatísticas de índices de preços de commodities (geral e mineral). Disponível em: <http://www.ipeadata.gov.br>. Acesso em: 30 de maio de 2013.

INSTITUTO JONES DOS SANTOS NEVES (IJSN, 2012). Investimentos previstos para o Espírito 2011-2016. Vitória-ES, 2012. Disponível em: $<$ www.ijsn.es.gov.br>. Acesso em: 01 de outubro de 2012. 
KWIATKOWSKI, D.; PHILLIPS, P.C.B.; SCHMIDT, P.; SHIN, Y. "Testing the null hypothesis of stationarity against the alternative of unit root". Journal of Econometrics, v. 54, n. 1, p. 159-178, 1992.

OREIRO, J. L.; FEIJÓ, C. A. "Desindustrialização: conceituação, causas, efeitos e o caso brasileiro". Revista de Economia Política, v. 30, n. 2, São Paulo, abril-junho de 2010.

MACKINNON, J. G. Critical values for cointegration tests. In: ENGLE, R. F.; GRANGER, C. W. J. (Ed.). Long-run economic relationships: readings in cointegration. Oxford Univ., 1991.

MAGALHÃES, M. A. "Preços de commodities e nível de atividade em uma pequena economia aberta: evidências empíricas para o estado do Espírito Santo". Economia e Sociedade, v.20, n.3 (43), p. 533-566, Dez. 2011.

MAGALHÃES, M. A.; TOSCANO, V. N. "Grau de abertura da economia do estado do Espírito Santo no período $1^{\circ}$ trim./04 - $2^{\circ}$ trim./09". Indicadores Econômicos FEE, v. 37, n. 4, 2009.

MINISTÉRIO DO TRABALHO E EMPREGO (RAIS/MTE, 2013). Relação Anual de Informações Sociais. Disponível em: <http://www.mte.gov.br/>. Acesso em: 30 de maio de 2013.

MARQUETTI, A. "Progresso técnico, distribuição e crescimento na economia brasileira: 1955-1998". Estudos Econômicos, Vol. 32, N.1, 2002.

MOTA, F. C. de M. Integração e dinâmica regional: o caso capixaba (1960-2000). 161 f. Tese (doutorado) - Universidade Estadual de Campinas, Instituto de Economia, 2002.

NASSIF, A. "Há evidências de desindustrialização no Brasil?" Revista de Economia Política, Vol. 28, $\mathrm{n}^{\circ} 1,2008$.

NEWEY, W.; WEST, K. "A simple positive semi-definite, heteroskedasticity and autocorrelation consistent covariance matrix," Econometrica, 55, 703-708, 1987. 
NONNENBERG, M. J. B.; LAMEIRAS, M. A. P. "Preços das commodities e o IPA". In: Boletim de conjuntura $n^{\circ}$ 69. Brasília: IPEA, junho de 2005.

PEREIRA, G. H. Política industrial e localização de investimentos e o caso do Espírito Santo. 1 ed. Vitória: EDUFES, 1998.

PHILLIPS, P. C. B.; PERRON, P. "Testing for a unit root in time series regression". Biometrika, v. 75, n. 3, p. 335-346, 1988.

ROCHA, H. C. "Formação econômica do Espírito Santo e sua lógica empresarial". In: GUALBERTO, João, DAVEL, Eduardo. (orgs.). Inovações organizacionais e relações do trabalho: ensaios sobre o Espírito Santo. Vitória: EDUFES, 1998. p. 33-75.

, COSSETTI, Maria da Penha. Dinâmica cafeeira e constituição da indústria no Espírito Santo - 1850/1930. Vitória: UFES/NEP/COPLAN/IJSN/GERES, 1983.

MORANDI, A. M.. Cafeicultura e Grande Indústria: a transição no Espírito Santo 1955-1985. 1 ed. Vitória: Fundação Ceciliano Abel de Almeida, 1991.

ROWTHORN, R.; RAMASWAMY, R. "Growth, trade, and deindustrialization". Staff Papers, IMF, v. 46, n. 1, p. 18-41, 1999.

SCATOLIN, F. D.; VARGAS DA CRUZ, M. J.; PORCILE, G.; NAKABASHI, L. "Desindustrialização? Uma análise comparativa entre Brasil e Paraná". Indicadores Econômicos FEE, v. 35, p. 105-120, 2007.

SECRETARIA DE ESTADO DE ECONOMIA E PLANEJAMENTO (SEP). Espírito Santo 2025: plano de desenvolvimento. Vitória: SEP/MACROPLAN, 2006.

SOARES, C.; TEIXEIRA, J. R. "Uma abordagem econométrica do processo de desindustrialização no caso brasileiro: elementos para o debate". XXXVIII Encontro Nacional de Economia (ANPEC), Salvador, Bahia, 2010. SOARES, C.; MUTTER, A.; OREIRO, J. L. Uma análise empírica dos determinantes da desindustrialização no caso brasileiro (1996-2008). 
Brasília: Departamento de Economia da UnB, 2011. Texto para discussão $n^{\circ} 361$.

SONAGLIO, C. M.; ZAMBERLAN, C. O.; EUSTÁQUIO DE LIMA, J.; CAMPOS, A. C. "Evidências de desindustrialização no Brasil: uma análise com dados em painel". Economia Aplicada, v. 14, n. 4, 2010, p. 347-372.

SQUEFF, G. C. "Controvérsias sobre a desindustrialização no Brasil". IV Encontro da Associação Keynesiana Brasileira, Rio de Janeiro, 2011.

TREGENNA, F. "Characterizing deindustrialization: an analysis of changes in manufacturing employment and output internationally". Cambridge Journal of Economics, Vol. 33, 2009.

Submetido em 17/03/2014

Aprovado em 16/11/2015

Sobre o autor

Sávio Bertochi Caçador

Mestre em Economia pela UFES. Economista do Banco de Desenvolvimento do Espírito Santo (BANDES).

Endereço: Av. Princesa Isabel 54, Centro. 29010-906 - Vitória - ES - Brasil.

E-mail: saviobertochi@bandes.com.br 


\section{Anexo 1. Valor adicionado do Espírito Santo (1947-2010), em R\$1.000,00 de 2000 (deflator implícito do PIB)}

\begin{tabular}{|c|c|c|c|c|c|c|}
\hline Anos & Agropecuária (A) & Indústria (B) & Serviços (C) & $\begin{array}{l}\text { Valor Adicionado } \\
(\mathrm{D}=\mathrm{A}+\mathrm{B}+\mathrm{C})\end{array}$ & População (E) & $\begin{array}{l}\text { VAT per capita } \\
(\mathrm{F}=\mathrm{D} / \mathrm{E})\end{array}$ \\
\hline 1947 & $309.417,19$ & $45.292,64$ & $325.092,24$ & \begin{tabular}{|r|}
$679.802,07$ \\
\end{tabular} & 901.352 & 754,20 \\
\hline 1948 & $331.658,00$ & $58.713,64$ & $339.845,17$ & $730.216,81$ & 915.252 & 797,83 \\
\hline 1949 & $507.889,22$ & $71.671,09$ & $422.503,06$ & $1.002 .063,37$ & 929.153 & $1.078,47$ \\
\hline 1950 & $513.199,61$ & $72.394,62$ & $434.070,61$ & $1.019 .664,84$ & 957.238 & $1.065,22$ \\
\hline 1951 & $703.797,63$ & $60.594,63$ & $527.212,37$ & $1.291 .604,63$ & 1.026 .909 & $1.257,76$ \\
\hline 1952 & & & $476.989,14$ & $1.044 .357,33$ & 1.061 .744 & 983,62 \\
\hline 1953 & $596.641,36$ & $61.121,11$ & $498.435,79$ & $1.156 .198,26$ & 1.096 .580 & $1.054,37$ \\
\hline 1954 & $578.773,08$ & $65.433,86$ & $512.688,39$ & $1.156 .895,33$ & 1.131 .415 & $1.022,52$ \\
\hline 1955 & $619.755,64$ & $71.334,35$ & $589.364,02$ & $1.280 .454,01$ & 1.166 .251 & $1.097,92$ \\
\hline 1956 & $563.519,28$ & $66.532,20$ & $636.964,25$ & $1.267 .015,73$ & 1.201 .086 & $1.054,89$ \\
\hline 1957 & & & & $1.429 .372,16$ & 1.235 .922 & $1.156,52$ \\
\hline 1958 & $559.977,65$ & $61.050,65$ & $706.663,59$ & $1.327 .691,89$ & 1.270 .757 & $1.044,80$ \\
\hline 1959 & $542.821,20$ & $74.303,52$ & $680.300,26$ & $1.297 .424,98$ & 1.305 .593 & 993,74 \\
\hline 1960 & $594.795,86$ & $75.833,94$ & $753.622,49$ & $1.424 .252,29$ & 1.418 .348 & $1.004,16$ \\
\hline 1961 & $453.052,68$ & $81.564,08$ & $806.209,48$ & $1.340 .826,24$ & 1.449 .486 & 925,04 \\
\hline 1962 & & & & $2.694,78$ & 1.465 .055 & $1.066,65$ \\
\hline 1963 & 2,48 & $112.690,96$ & $958.842,62$ & $1.611 .396,06$ & 1.480 .624 & $1.088,32$ \\
\hline 1964 & $948.487,89$ & $131.701,03$ & $1.121 .569,63$ & $2.201 .758,55$ & 1.496 .193 & $1.471,57$ \\
\hline 1965 & $720.687,29$ & $128.614,36$ & $1.071 .731,16$ & $1.921 .032,81$ & 1.511 .763 & $1.270,72$ \\
\hline 1966 & $664.001,35$ & $73.834,97$ & $1.167 .986,71$ & $1.905 .823,03$ & 1.527 .332 & $1.247,81$ \\
\hline 1967 & & $145.639,92$ & $1.249 .609,84$ & $2.059 .335,99$ & 1.542 .901 & $1.334,72$ \\
\hline 1968 & $927.634,02$ & $168.621,50$ & $1.407 .220,38$ & $2.503 .475,90$ & 1.558 .470 & $1.606,37$ \\
\hline 1969 & $704.178,49$ & $197.983,93$ & $1.448 .901,41$ & $2.351 .063,83$ & 1.574 .039 & $1.493,65$ \\
\hline 1970 & $697.539,94$ & $441.952,78$ & $2.218 .638,48$ & $3.358 .131,20$ & 1.599 .324 & $2.099,72$ \\
\hline 1971 & $784.452,83$ & $594.287,66$ & $2.417 .931,44$ & $3.796 .671,93$ & 1.668 .444 & $2.275,58$ \\
\hline 1972 & $827.909,27$ & $670.455,11$ & $2.517 .577,92$ & $4.015 .942,29$ & 1.703 .004 & $2.358,15$ \\
\hline 1973 & $871.365,71$ & $746.622,55$ & $2.617 .224,40$ & $4.235 .212,66$ & 1.737 .563 & $2.437,44$ \\
\hline 1974 & $914.822,16$ & $822.789,99$ & $2.716 .870,87$ & $4.454 .483,02$ & 1.772 .123 & $2.513,64$ \\
\hline 1975 & $1.002 .423,25$ & $147.371,10$ & $7.807,23$ & $5.037 .601,58$ & 1.806 .683 & $2.788,31$ \\
\hline 1976 & $1.173 .113,84$ & $1.682 .499,60$ & $3.538 .544,53$ & $6.394 .157,97$ & 1.841 .243 & $3.472,74$ \\
\hline 1977 & $1.258 .459,14$ & $950.063,85$ & $3.863 .913,18$ & $7.072 .436,17$ & 1.875 .803 & $3.770,35$ \\
\hline 1978 & $1.343 .804,44$ & $2.217 .628,09$ & $4.189 .281,83$ & $7.750 .714,36$ & 1.910 .363 & $4.057,20$ \\
\hline 1979 & $1.429 .149,74$ & $2.485 .192,34$ & $4.514 .650,48$ & $8.428 .992,56$ & 1.944 .923 & $4.333,84$ \\
\hline 1980 & $1.636 .678,31$ & $4.035 .525,03$ & $5.479 .816,21$ & $11.152 .019,55$ & 2.023 .338 & $5.511,69$ \\
\hline 1981 & $1.962 .877,01$ & $4.396 .851,71$ & $5.566 .840,76$ & $11.926 .569,48$ & 2.108 .873 & $5.655,42$ \\
\hline 1982 & $2.125 .976,35$ & $4.577 .515,06$ & $5.610 .353,04$ & $12.313 .844,45$ & 2.151 .640 & $5.723,00$ \\
\hline 1983 & $2.289 .075,70$ & $4.758 .178,40$ & $5.653 .865,32$ & $12.701 .119,41$ & 2.194 .407 & $5.787,95$ \\
\hline 1984 & $2.452 .175,05$ & $4.938 .841,74$ & 5.697.377,59 & $13.088 .394,38$ & 2.237 .174 & $5.850,41$ \\
\hline 1985 & $2.893 .986,51$ & $5.248 .314,00$ & $5.746 .127,68$ & $13.888 .428,19$ & 2.279 .942 & $6.091,57$ \\
\hline 1986 & $3.688 .887,53$ & $5.431 .963,34$ & $5.610 .369,92$ & $14.731 .220,79$ & 2.322 .709 & $6.342,26$ \\
\hline 1987 & $1.514 .250,36$ & $5.753 .316,87$ & $6.188 .823,87$ & $13.456 .391,10$ & 2.365 .476 & $5.688,66$ \\
\hline 1988 & $2.068 .992,95$ & $6.288 .839,64$ & $6.476 .492,35$ & $14.834 .324,94$ & 2.408 .244 & $6.159,81$ \\
\hline & $2.729 .967,96$ & $7.067 .504,57$ & $6.802 .074,00$ & $16.599 .546,53$ & 2.451 .011 & $6.772,53$ \\
\hline 1990 & $919.690,71$ & $5.563 .233,56$ & $6.419 .563,11$ & $12.902 .487,38$ & 2.493 .778 & $5.173,87$ \\
\hline
\end{tabular}


A economia do Espírito Santo está sofrendo um processo de desindustrialização?

\begin{tabular}{r|r|r|r|r|r|r}
1991 & $918.964,76$ & $5.806 .196,85$ & $7.601 .643,73$ & $14.326 .805,34$ & 2.600 .618 & $5.509,00$ \\
\hline 1992 & $956.394,93$ & $6.761 .437,75$ & $7.197 .580,94$ & $14.915 .413,62$ & 2.649 .747 & $5.629,00$ \\
\hline 1993 & $1.171 .579,58$ & $6.743 .875,23$ & $7.681 .352,76$ & $15.596 .807,57$ & 2.698 .687 & $5.779,41$ \\
\hline 1994 & $1.941 .250,57$ & $6.345 .212,83$ & $8.153 .414,52$ & $16.439 .877,92$ & 2.743 .243 & $5.992,86$ \\
\hline 1995 & $1.454 .668,70$ & $5.883 .479,47$ & $8.169 .146,69$ & $15.507 .294,86$ & 2.786 .692 & $5.564,77$ \\
\hline 1996 & $1.652 .685,75$ & $6.192 .583,79$ & $8.811 .483,93$ & $16.656 .753,47$ & 2.802 .707 & $5.943,09$ \\
\hline 1997 & $1.284 .128,17$ & $6.363 .811,42$ & $9.168 .976,81$ & $16.816 .916,40$ & 2.853 .098 & $5.894,27$ \\
\hline 1998 & $1.503 .688,40$ & $5.977 .275,01$ & $9.575 .000,71$ & $17.055 .964,12$ & 2.895 .547 & $5.890,41$ \\
\hline 1999 & $1.300 .964,20$ & $6.367 .990,96$ & $9.367 .058,94$ & $17.036 .014,10$ & 2.938 .062 & $5.798,38$ \\
\hline 2000 & $1.626 .283,52$ & $6.838 .242,39$ & $9.965 .220,76$ & $18.429 .746,67$ & 2.980 .729 & $6.182,97$ \\
\hline
\end{tabular}

\section{Continuação}

\begin{tabular}{c|c|r|r|r|r|r}
\hline Anos & $\begin{array}{c}\text { Agropecuária } \\
(\mathbf{A})\end{array}$ & Indústria (B) & Serviços (C) & $\begin{array}{c}\text { Valor Adicionado } \\
(\mathbf{D}=\mathbf{A}+\mathbf{B}+\mathbf{C})\end{array}$ & População (E) & $\begin{array}{r}\text { VAT per capita } \\
(\mathrm{F}=\mathrm{D} / \mathrm{E})\end{array}$ \\
\hline 2001 & $925.101,53$ & $6.700 .281,78$ & $9.834 .996,57$ & $17.460 .379,88$ & 3.155 .016 & $5.534,17$ \\
\hline 2002 & $1.501 .170,13$ & $5.847 .423,30$ & $11.067 .173,89$ & $18.415 .767,32$ & 3.201 .722 & $5.751,83$ \\
\hline 2003 & $1.611 .314,61$ & $5.726 .985,46$ & $11.189 .592,36$ & $18.527 .892,43$ & 3.250 .219 & $5.700,51$ \\
\hline 2004 & $2.053 .867,19$ & $7.187 .180,26$ & $12.707 .096,32$ & $21.948 .143,77$ & 3.352 .024 & $6.547,73$ \\
\hline 2005 & $2.091 .463,03$ & $8.049 .816,21$ & $13.712 .187,51$ & $23.853 .466,75$ & 3.408 .365 & $6.998,51$ \\
\hline 2006 & $2.405 .911,30$ & $8.613 .370,44$ & $14.297 .220,01$ & $25.316 .501,75$ & 3.464 .285 & $7.307,86$ \\
\hline 2007 & $2.517 .363,51$ & $9.362 .148,67$ & $15.285 .569,28$ & $27.165 .081,46$ & 3.351 .669 & $8.104,94$ \\
\hline 2008 & $1.965 .011,04$ & $10.351 .985,84$ & $16.415 .782,13$ & $28.732 .779,01$ & 3.453 .648 & $8.319,54$ \\
\hline 2009 & $1.768 .231,27$ & $7.788 .537,46$ & $16.608 .369,00$ & $26.165 .137,73$ & 3.487 .199 & $7.503,20$ \\
\hline 2010 & $1.903 .097,66$ & $10.830 .394,12$ & $17.388 .130,18$ & $30.121 .621,95$ & 3.514 .952 & $8.569,57$ \\
\hline
\end{tabular}

Fonte: IPEADATA (2013a).

Notas:

1) Fontes e metodologia de estimativa do Valor Adicionado

O site do IPEADATA fornece as seguintes fontes para os dados de Valor Adicionado expostos na tabela A.1:

a) para 2002-2006: Sistema de Contas Regionais Referência 2002 do IBGE.

b) para 1985-2001: antigo Sistema de Contas Regionais do IBGE. Conceito utilizado a partir de 1985 a preços básicos.

c) Para os anos de 1970, 1975 e 1980: Produto Interno Bruto a custo de fatores elaborado pelo IBGE.

d) Para os anos de 1971 a 1974: utilizou-se a taxa média geométrica dos anos de 1970 e 1975.

e) Para os anos de 1976 a 1979: utilizou-se a taxa média geométrica dos anos de 1975 e 1980.

f) Para os anos de 1981 a 1984: utilizou-se a taxa média geométrica dos anos de 1980 e 1985.

g) Para os anos de 1939, 1947 a 1969: Produto Interno Líquido a custo de fatores elaborado pela FGV.

Além disso, o site alerta que as estimativas do PIB não são consistentes com o PIB por atividades. O problema se deve à utilização de conceitos distintos: o PIB referese a preços de mercado e as atividades a preços básicos.

Para resolver esse problema, estimou-se o Valor Adicionado Total da seguinte forma:

Redes (St. Cruz Sul, Online), v. 20, n 3 - Suplemento, p. 341 - 362, set./dez. 2015368 
$\mathrm{VAT}=\mathrm{VA}_{\mathrm{agropecuária}}+\mathrm{VA}_{\text {indústria }}+\mathrm{VA}_{\text {serviços }}$

\section{2) Fontes e metodologia de estimativa da população}

O site do IPEADATA fornece as seguintes fontes para os dados de população expostos na tabela A.1:

a) 1940, 1950, 1960, 1970, 1980, 1991, 2000 e 2010: população residente total, segundo Censos do IBGE.

b) 1996 e 2007: população residente total, segundo Contagem do IBGE.

c) 1992, 1993, 1994, 1995, 1997, 1998, 1999, 2001, 2002, 2003, 2004, 2005, 2006, 2008, 2009: estimativas da população residente em $1^{\circ}$ julho, segundo IBGE.

Para os demais anos, empregou-se a seguinte metodologia:

i) Nos casos de 1947, 1948 e 1949: utilizou-se a taxa média geométrica do período intercensitário 1940-1950.

ii) Nos casos de 1951 a 1959: utilizou-se a taxa média geométrica do período intercensitário 1950-1960.

iii) Nos casos de 1951 a 1959: utilizou-se a taxa média geométrica do período intercensitário 1950-1960.

iv) Nos casos de 1961 a 1969: utilizou-se a taxa média geométrica do período intercensitário 1960-1970.

v) Nos casos de 1971 a 1979: utilizou-se a taxa média geométrica do período intercensitário 1970-1980.

vi) Nos casos de 1981 a 1990: utilizou-se a taxa média geométrica do período intercensitário 1980-1991.

Anexo 2. Quantidade de empregos formais no Espírito Santo, por setores (19852010)

\begin{tabular}{rrrrr|r|r|r|r|r|r|r}
\hline $\begin{array}{c}\text { Anos/ } \\
\text { Setores }\end{array}$ & $\begin{array}{c}\text { Ext. } \\
\text { Mineral }\end{array}$ & $\begin{array}{l}\text { Ind. de } \\
\text { Transf. }\end{array}$ & $\begin{array}{c}\text { Serv. Ind. } \\
\text { de Util. } \\
\text { Pública }\end{array}$ & Construção & Comércio & Serviços & $\begin{array}{c}\text { Adm. } \\
\text { Pública }\end{array}$ & Agropecuária & Outros & Total \\
\hline 1985 & 13.431 & 57.382 & 4.434 & 17.827 & 42.939 & 93.160 & 81.767 & 4.846 & 897 & 316.683 \\
1986 & 13.728 & 63.403 & 4.556 & 19.996 & 50.044 & 101.550 & 86.374 & 4.917 & 851 & 345.419 \\
1987 & 13.875 & 62.219 & 4.449 & 19.840 & 49.394 & 106.247 & 89.783 & 3.741 & 8.817 & 358.365 \\
1988 & 5.708 & 64.606 & 4.345 & 22.436 & 49.963 & 117.577 & 92.900 & 4.267 & 16.293 & 378.095 \\
1989 & 6.327 & 65.444 & 5.410 & 26.297 & 54.126 & 128.508 & 84.400 & 6.577 & 18.963 & 396.052 \\
1990 & 6.083 & 60.541 & 5.337 & 22.363 & 51.643 & 122.166 & 83.861 & 6.262 & 24.111 & 382.367 \\
1991 & 5.820 & 58.711 & 5.384 & 21.747 & 49.539 & 121.580 & 87.119 & 6.282 & 30.172 & 386.354 \\
1992 & 5.848 & 53.771 & 5.508 & 20.820 & 47.062 & 119.197 & 85.335 & 5.923 & 29.728 & 373.192 \\
1993 & 6.361 & 54.729 & 5.495 & 20.756 & 49.460 & 112.850 & 89.161 & 6.268 & 47.361 & 392.441 \\
1994 & 6.520 & 59.549 & 6.147 & 25.107 & 68.265 & 127.700 & 89.057 & 13.372 & 15.884 & 411.601 \\
1995 & 5.761 & 60.784 & 5.868 & 26.862 & 67.774 & 139.918 & 93.966 & 16.672 & 2.942 & 420.547 \\
1996 & 5.668 & 63.723 & 5.649 & 28.740 & 73.215 & 137.621 & 93.476 & 17.215 & 964 & 426.271 \\
1997 & 5.292 & 62.639 & 5.506 & 35.656 & 78.892 & 136.741 & 74.010 & 17.920 & 150 & 416.806 \\
1998 & 10.072 & 61.003 & 5.435 & 23.911 & 81.858 & 136.783 & 94.204 & 18.690 & 15 & 431.971 \\
1999 & 6.958 & 69.516 & 5.227 & 23.537 & 84.456 & 142.162 & 99.029 & 20.496 & 0 & 451.381
\end{tabular}


A economia do Espírito Santo está sofrendo um processo de desindustrialização?

\begin{tabular}{rrrrrrrrrrr}
2000 & 10.787 & 70.450 & 5.049 & 23.437 & 91.160 & 141.347 & 104.500 & 24.964 & 4 & 471.698 \\
2001 & 11.435 & 68.894 & 5.590 & 28.696 & 99.070 & 153.833 & 121.315 & 26.320 & 0 & 515.153 \\
2002 & 11.815 & 73.086 & 5.714 & 30.519 & 107.366 & 162.616 & 132.987 & 27.498 & 0 & 551.601 \\
2003 & 13.320 & 75.719 & 6.598 & 27.840 & 114.438 & 171.135 & 129.557 & 26.694 & 0 & 565.301 \\
2004 & 14.084 & 84.683 & 6.324 & 30.571 & 122.714 & 186.888 & 119.930 & 28.399 & 0 & 593.593 \\
2005 & 15.532 & 91.827 & 6.827 & 39.498 & 134.491 & 198.915 & 138.602 & 30.652 & 0 & 656.344 \\
2006 & 12.383 & 103.365 & 7.127 & 44.008 & 144.584 & 217.853 & 147.701 & 30.359 & 0 & 707.380 \\
2007 & 13.110 & 105.571 & 7.708 & 47.668 & 156.392 & 230.971 & 160.763 & 29.376 & 0 & 751.559 \\
2008 & 12.207 & 110.361 & 8.256 & 54.331 & 164.663 & 249.679 & 146.242 & 30.551 & 0 & 776.290 \\
2009 & 11.958 & 113.887 & 8.835 & 54.723 & 167.909 & 266.623 & 162.470 & 30.501 & 0 & 816.906 \\
2010 & 12.588 & 117.402 & 9.109 & 60.275 & 178.575 & 285.809 & 167.188 & 29.475 & 0 & 860.421 \\
\hline
\end{tabular}

Fonte: RAIS/MTE (2013). 